\title{
Acknowledgments
}

IN BRINGING this project to fruition, I am indebted to a number of individuals and institutions. First, I wish to acknowledge the role of the late Professor Anthony Sutcliffe, under whom, as a MA student at Leicester University, I was introduced to the field of planning history. Without Tony's support from that time, aside from his capacity to articulate his enormous knowledge of cities, their histories, and their environmental designs, I would not have had my curiosity piqued as to why cities evolve as they do, and consequently why they have the urban forms they have. From the bedrock of tutorials in the Attenborough Tower (and the subsequent occasional get-togethers in pubs in Nottingham), I have ultimately been inspired to investigate the history of urban design in the Philippines. Moreover, thanks to his encouragement, I became genuinely interested, for the first time, in learning for the sake of learning: hitherto my education had always been something I felt thrust upon me rather than something I could enjoy for its own sake. Thank you, Tony!

With reference to the Chinese University of Hong Kong (CUHK), I would like to acknowledge the Department of History for granting me the freedom to research academic fields of genuine appeal to me, and I extend my gratitude to the Faculty of Arts for their Direct Grants for Research in initiating my investigations into Philippine urban history and for the Publication Subvention Fund (2016-2017) in supporting this publication. My gratitude to the Faculty of Arts is deepened by their giving of the Humanities Fellowship to me in 2015 so as to permit me additional time for my research process. I am also particularly grateful to the Research Grants Council (RGC) in Hong Kong. Without their generous funding this project would not have occurred, and consequently my ability to access archives outside of Hong Kong would have been severely limited. Without the RGC General Fund for Research, and 
the grant awarded to me, the project upon which this book is based quite simply would not have got started.

Mention, and so appreciation, must be given also to the numerous archivists who have given me assistance over the course of the past few years in Hong Kong, the Philippines, and United States. Particular thanks go to the staff of the Rizal Library at Ateneo de Manila University, peers at the University of the Philippines-Diliman-particularly Professor Gerard Lico and Dan Silvestre-staff at the Library of Congress, National Archives II in Maryland, the Art Institute of Chicago, National Library of the Philippines, as well as archivists at Yale University and Harvard University. Furthermore, without the support of friends in different countries-Stael Alvarenga de Periera Costa, Renato Leao, Tony Potts, and Murat Cetin, for instance-the road to completing this book would have been much rockier: thank you for your support. Additionally, it would be impossible to not acknowledge the assistance given by Ms. Lin Jin, my research assistant, who offered great time and effort to the cause of investigating the history of urban planning in the Philippines. Finally, I'd like to thank my family for all their support: Alexandra, Anaé, and Emeline ... this book is for you! 


\section{Cities and llationhood}


